\title{
Effect of ball milling time on nanocrystalline powders and bulk ultrafine-grained Mg-3Al-Zn alloy
}

\author{
Jie Feng ${ }^{a}$, Hong-fei Sun, and Wen-bin Fang \\ School of Materials Science and Engineering, Harbin Institute of Technology, Harbin 150001, \\ PR China
}

\begin{abstract}
Bulk ultrafine-grained Mg-3Al-Zn alloy has been made of elemental powders by mechanical milling, vacuum hot pressing and warm extrusion sequentially. As the only variable, ball milling time was $20 \mathrm{~h}, 40 \mathrm{~h}, 60 \mathrm{~h}$ and $80 \mathrm{~h}$, respectively. Microstructural studies and mechanical strength were characterized by SEM, XRD, TEM and tensile tests. At $60 \mathrm{~h}$, the particle size of the milled powders decreased to $10 \mu \mathrm{m}$. With extension of time, the grain sizes of nanocrystalline powders were $41,39.5,38.5$ and $38 \mathrm{~nm}$. Under the same hot pressing and extrusion conditions, the grain sizes of extruded materials were 600, 565, 555 and $550 \mathrm{~nm}$, respectively. The results of tensile tests showed that increasing milling time under $60 \mathrm{~h}$ improved the strength of the extruded alloys, however, reduced the ductility due to lower relative density and more defects. This also indicated that better ductility with high strength should be obtained if densification process was further improved. Meanwhile, the high ultimate strength of $419 \mathrm{MPa}$ results from oxide dispersion strengthening and dislocation strengthening besides grain refinement strengthening.
\end{abstract}

\section{Introduction}

Magnesium alloys possess low density, high specific strength and stiffness, therefore, they are attractive for lightweight structural applications in the transportation industry [1]. However, the symmetry of the hexagonal close-packed crystal structure results in poor formability and ductility near room temperature [2]. According to Hall-Petch relationship, grain refinement is one of the most effective methods to improve the strength of the material, the resulting ultrafine-grained (UFG) structure can bring about high strength and even superplasticity at high strain rates and low temperatures [3-5]. Of the many techniques used for achieving UFG microstructures, such as equal channel angular extrusion (ECAE) [6], friction stir processing(FSP) [7], accumulative roll bonding (ARB) [8], high-pressure torsion (HPT) [9] and powder metallurgy (PM) [10], PM was an effective technique to synthesize high strength UFG $\mathrm{Mg}$ alloys [11-15]. A UFG structure is more easily achieved in precipitate-hardened $\mathrm{Mg}$ alloys or Mg-based composites due to the effective pining effect from the precipitates or added ceramic particles on the grain boundaries [16-19].

\footnotetext{
${ }^{\text {a }}$ Corresponding author: fjhit@sina.cn
}

This is an Open Access article distributed under the terms of the Creative Commons Attribution License 4.0, which permits unrestricted use, distribution, and reproduction in any medium, provided the original work is properly cited. 


\section{MATEC Web of Conferences}
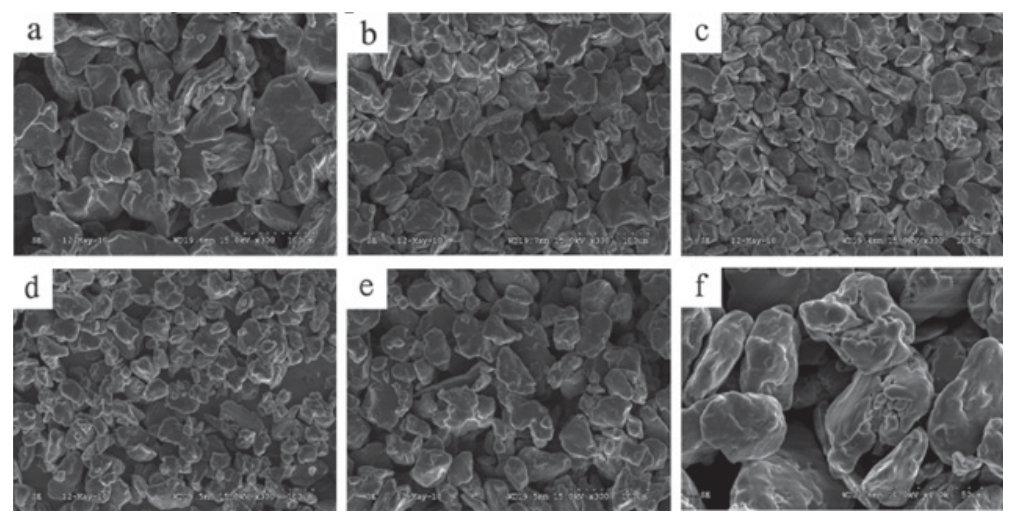

Figure 1. The morphology of the milled Mg-3Al-Zn powders: (a) $0 \mathrm{~h} \mathrm{(b)} 20 \mathrm{~h} \mathrm{(c)} 40 \mathrm{~h} \mathrm{(d)} 60 \mathrm{~h}$ (e) $80 \mathrm{~h}$ and (f) $20 \mathrm{~h}$ partial enlarged detail.

For pure Mg or solute-solution hardened Mg alloys (such as AZ31) with a low content of alloying elements, it is difficult to achieve a UFG microstructure due to the rapid growth kinetics of the singlephase grains. This paper studies the effect of ball milling time on the microstructure and grain refinement of $\mathrm{Mg}-3 \mathrm{Al}-\mathrm{Zn}$ powders, further on the microstructure and tensile properties of the bulk ultrafine-grained $\mathrm{Mg}-3 \mathrm{Al}-\mathrm{Zn}$ alloy. Moreover, the reason for high strength of bulk Mg-3Al-Zn alloy is investigated.

\section{Experimental procedure}

The alloy powder with a nominal composition of $\mathrm{Mg}-3 \mathrm{Al}-\mathrm{Zn}$ was produced by mechanical milling of a mixture of $\mathrm{Mg}$ powder $(99 \%, 325 \mathrm{mesh}), \mathrm{Zn}$ powder $(99 \%, 325 \mathrm{mesh}$ ) and $\mathrm{Al}$ powder $(99.5 \%$, 325 mesh) under high purity argon (99\%). The milling was carried out with a QM21SP4 planetary ball milling machine. The ball milling parameters were following: shaft rotation was $360 \mathrm{rpm}$ and the ratio of ball to powder was $40: 1$. The milling time was $20 \mathrm{~h}, 40 \mathrm{~h}, 60 \mathrm{~h}$ and $80 \mathrm{~h}$. During the ball milling, the vial was filled with high purity argon (99.9\% pure) to ensure an inert atmosphere. After ball milling, the powders were put into an $\mathrm{Al}$ container of $35 \mathrm{~mm}$ in diameter and about $65 \mathrm{~mm}$ in length. The cans were sintered for $40 \mathrm{~min}$ at $633 \mathrm{~K}$ in a vacuum furnace and then pressed under a vacuum better than $1 \times 10^{-3} \mathrm{~Pa}$. Then the sintered compacts with canning were hot-extruded at $473 \mathrm{~K}$, under an extrusion ratio 6.25 and an extrusion rate $22 \mathrm{~mm} / \mathrm{s}$ using graphite as lubricant. The microstructure of the milled powders and the extruded alloys were characterized using SEM, DSC, XRD and TEM, respectively. According to Archimedes principle, the density $\rho$ of the extruded bulk alloys were measured using an ESJ200-4 electronic balance, with an accuracy of $\pm 0.0001 \mathrm{~g}$. The immersion fluid was distilled water.

\section{Results and discussion}

\subsection{Microstructure evolution of the milled powder particles}

The SEM micrographs of the powders milled for $0 \mathrm{~h}, 20 \mathrm{~h}, 40 \mathrm{~h}, 60 \mathrm{~h}$ and $80 \mathrm{~h}$ are shown in Fig. 1. The particles of original powder possess an irregular, flake-like morphology. The particle size is distributed from a few $\mu \mathrm{m}$ to a few tens of $\mu \mathrm{m}$. This morphology is typical of Mg-based powders produced by the mechanical grinding of casting ingots. From the SEM observations and the statistical results of particle size, we can find that: with increasing of milling time, the microstructures of the milled powders become more and more homogenous and the particle size becomes smaller and smaller. After milling $20 \mathrm{~h}$, a majority of powder particles has changed to regular morphology, the average particle 

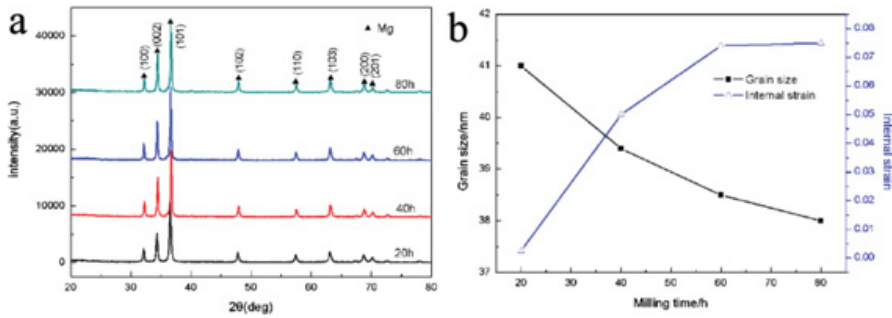

Figure 2. XRD analysis of the milled powders: (a) XRD pattern and (b) the mean grain size and internal strain of the milled powders.

size rapidly decreases to about $25 \mu \mathrm{m}$ and particle size distribution has become relatively homogeneous. After milling $60 \mathrm{~h}$, the average particle size has decreased to about $10 \mu \mathrm{m}$. To a large extent, paticle size distribution is more homogeneous. Then with further milling, the powders tend to form agglomerates due to cold welding, the average particle size of $80 \mathrm{~h}$-milled powders increases to about $13 \mu \mathrm{m}$, which implies that, when increasing milling time to $80 \mathrm{~h}$, the cold welding has been ahead of fracturing of powder particles.

\subsection{Crystal structure of nanocrystalline powders}

Figure 2 presents the XRD analysis of the milled powders under different milling time. As shown in Fig. 2(a), all of the diffraction peaks are readily indexed to various crystal planes of the hexagonal phase $\mathrm{Mg}$. No peaks for other phases can be detected, which indicates that the $\mathrm{Al}$ and $\mathrm{Zn}$ elements absolutely dissolve into the Mg matrix and form solid solution. The diffracted peaks become slightly broad after milling and the diffraction intensity became weaker, which suggests that grain refineness and lattice distortion take place during milling.

The mean grain size and internal strain measured from XRD diffraction was shown in Fig. 2(b). From the image, we can find that, the mean grain size of the powder after milling $20 \mathrm{~h}$ is $41 \mathrm{~nm}$. As the milling time goes to $80 \mathrm{~h}$, the mean grain size decreases to $38 \mathrm{~nm}$. The trend of mean grain size indicates a gradually balance between the recovery rate of grain and the birth rate of sub-grains. Moreover, the internal strain reaches $7.48 \%$ when milling to $80 \mathrm{~h}$, which illustrates that severe lattice distortion emerges in the milled powders. The main cause of lattice distortion in magnesium alloys are: (1) a large amount of defects such as dislocations and vacancies are introduced by evere plastic deformation; (2) Al atoms and zinc atoms dissolve into a fraction of $\mathrm{Mg}$ matrix in mechanical ball milling.

The bright field TEM micrographs and selected area electron diffraction (SAED) pattern, obtained from region with a diameter of $800 \mathrm{~nm}$, for the $\mathrm{Mg}-3 \mathrm{Al}-\mathrm{Zn}$ powders milled for $20 \mathrm{~h}$ and $80 \mathrm{~h}$ are shown in Fig. 3(a) and (b). The corresponding grain size distributions for these two cases are shown in Fig. 3(c) and (d). As shown in Fig. 3(a) and (b), the nanostructured powders are mainly composed of equiaxed grains, where distributes some lamellar structures about 2-4 nm, which are considered to be oxide particles introduced in mechanical ball milling. Moreover, from the microstructure, we can find that, some grains contain high density dislocations, the others almost are dislocation-free, which indicates that dynamic recovery or even dynamic recrystallization of the alloy powders occurs in mechanical ball milling. For the two milling time powders, the grains and grain boundaries are clearly observed. The SADP taken from the as-milled alloy exhibits the rings of diffracted spots, indicating the presence of grain boundaries with high angle of misorientation. Figure 3(c) and (d) shows the grain size distribution of the milled powders of $20 \mathrm{~h}$ and $80 \mathrm{~h}$ respectively, which is summarized by measuring 500 grain diameters in bright field images. From Fig. 3(c) and (d), we can see that, after $20 \mathrm{~h}$ milling, the equiaxed grains are about $25-60 \mathrm{~nm}$ surrounded by a few smaller grains $(<20)$ and some larger ones about 


\section{MATEC Web of Conferences}
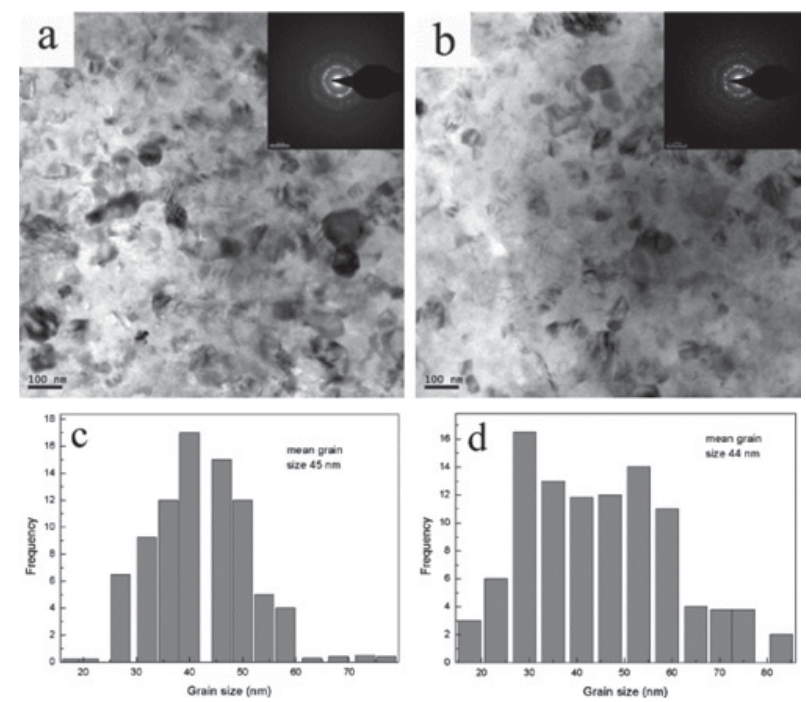

Figure 3. Bright field image (with SAED pattern as an insert) of Mg-3Al-Zn powders for different time: (a) $20 \mathrm{~h}$ and (b) $80 \mathrm{~h}$. The grain size distributions corresponding to the materials in (a) and (b) are shown in (c) and (d), respectively.

$60-80 \mathrm{~nm}$. The average grain size is about $45 \mathrm{~nm}$. Increasing milling time to $80 \mathrm{~h}$, the grain size distribution is more homogeneous, but the average grain size shows little change, which is different from XRD results.

\subsection{Density and microstructure of bulk ultrafine-fine grained alloy}

TEM observations of Mg-3Al-Zn alloy after 20, 40, 60 and $80 \mathrm{~h}$ milling durations and extruded at $200{ }^{\circ} \mathrm{C}$ are shown in Fig. 4. It is noticeable that there are no voids or pores at the interfaces and the powder particles are well bound for the three alloys. Near equiaxed nano-sized grains are introduced and grain boundries are well-defined for the four samples. After consolidation, the dense structured rods are extracted from the $\mathrm{Al}$ container. The statistical results for the grain size and relative density of the extruded alloys are shown in Fig. 5. The average density for tested $20 \mathrm{~h}, 40 \mathrm{~h}, 60 \mathrm{~h}$ and $80 \mathrm{~h}$ samples is $1.79084 \pm 0.006 \mathrm{~g} / \mathrm{cm}^{3}, 1.78519 \pm 0.006 \mathrm{~g} / \mathrm{cm}^{3}, 1.77900 \pm 0.006 \mathrm{~g} / \mathrm{cm}^{3}$ and $1.76844 \pm 0.006 \mathrm{~g} / \mathrm{cm}^{3}$, respectively. Because the nominal density of $\mathrm{Mg}-3 \mathrm{Al}-\mathrm{Zn}$ alloy is $1.82088 \mathrm{~g} / \mathrm{cm}^{3}$, the consolidated samples have the relative density of $98.35 \pm 0.3 \%, 98.04 \pm 0.3 \%, 97.70 \pm 0.3 \%$ and $97.12 \pm 0.3 \%$, respectively. We also can find that, increasing the milling time, results in the following change in microstructures: (a) the average grain size of the extruded alloys decreases. The variation trend of grain size for the extruded alloys is in correspondence with that for nanocrystalline powders. (b) dislocation density in grain interiors increases. The results prove that no further refinement of nanocrystalline powders results in no further refinement of the extruded alloys directly. Increasing milling time from $20 \mathrm{~h}$ to $80 \mathrm{~h}$, the grain size of the extruded alloys just decreases from about $600 \mathrm{~nm}$ to $550 \mathrm{~nm}$. However, further milling brings into a lot of defects which is not good to the mechanical properties of the extruded alloys.

\subsection{Mechanical properties}

Figure 6 shows true stress and true strain curves for the alloys extruded at $473 \mathrm{~K}$ with an extrusion ratio of 6.25. It is clear that the true stress and true strain curves of the ultrafine-grained samples show a 


\section{ICNFT 2015}
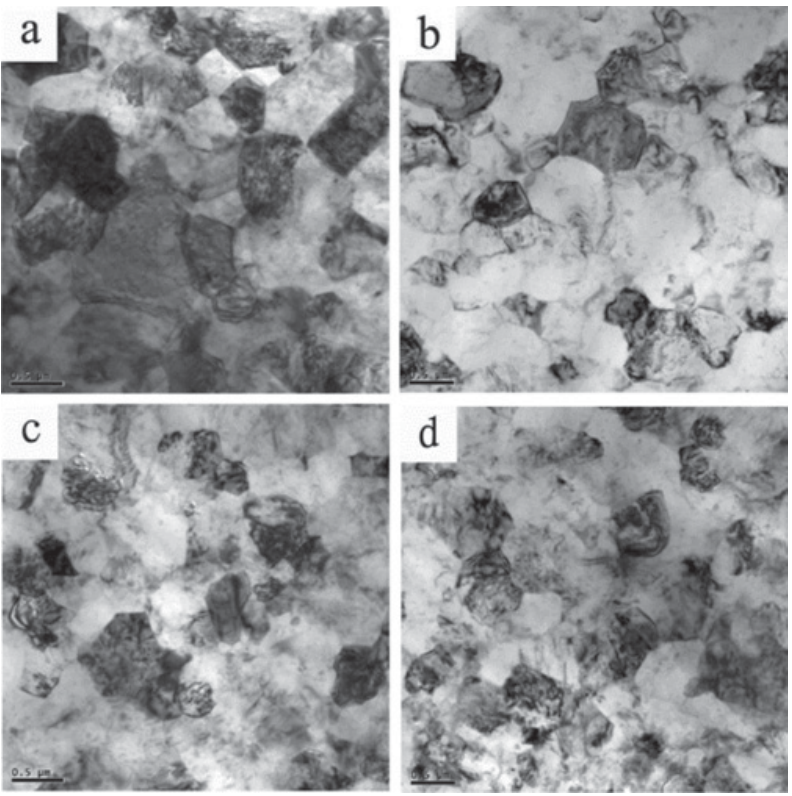

Figure 4. Bright field image of bulk Mg-3Al-Zn alloys extruded at $20{ }^{\circ} \mathrm{C}$ milled for different time: (a) $20 \mathrm{~h}$ (b) $40 \mathrm{~h}(\mathrm{c}) 60 \mathrm{~h}$ and (d) $80 \mathrm{~h}$.

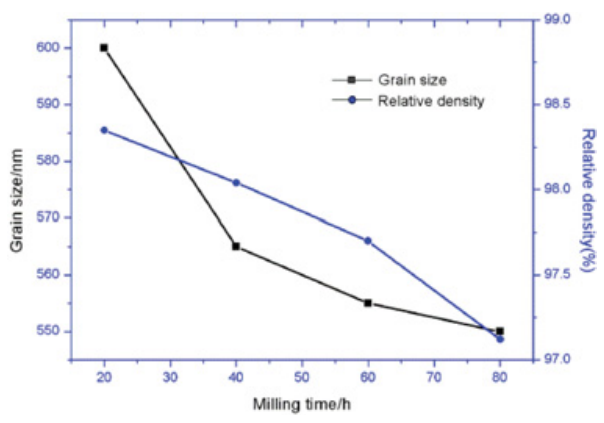

Figure 5. The grain size of the extruded alloys for different milling time.

perfect elastic-plastic characteristic, which is considered to be relative to ultrafine grain. With extension of milling time, the strength of the extruded alloy increases except $80 \mathrm{~h}$-milled sample. However, the plasticity decreases. The increase of strength is following Hall-Petch relationship, The $60 \mathrm{~h}$-milled sample with finer ultrafine grain shows a ultimate tensile strength of $419 \mathrm{MPa}$. By contrast to ultrafinegrained AZ31 alloy reported in the paper [20], the ultimate tensile strength of the 60-milled sample raises about $36.4 \%$. Besides grain refinement strengthening, the high strength is also due to oxide dispersion strengthening and dislocation strengthening, as shown in Fig. 7. By contrast with the $80 \mathrm{~h}-$ milled sample, the elongation of the $20 \mathrm{~h}$-milled sample reduces from $7.4 \%$ from $1.5 \%$. The lower plasticity with increasing the milling time is mainly due to the higher defects brought by mechanical milling without unconspicuous grain refinement and the lower consolidation density. 


\section{MATEC Web of Conferences}

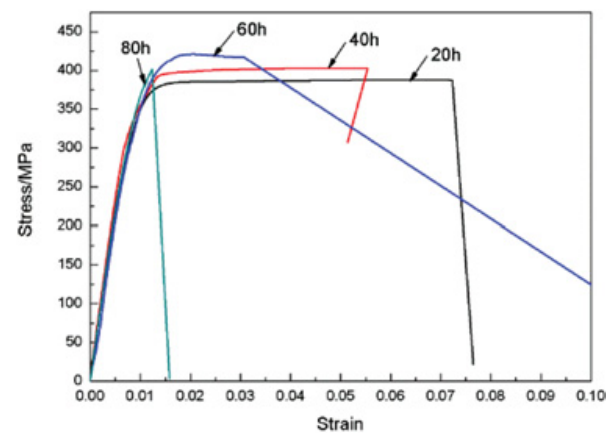

Figure 6. Stress-strain curves at room temperature with an initial strain rate of $10^{-3} \mathrm{~s}^{-1}$ for four as-extruded Mg-3Al-Zn alloys with the milling time of $20 \mathrm{~h}, 40 \mathrm{~h}, 60 \mathrm{~h}$ and $80 \mathrm{~h}$, respectively.
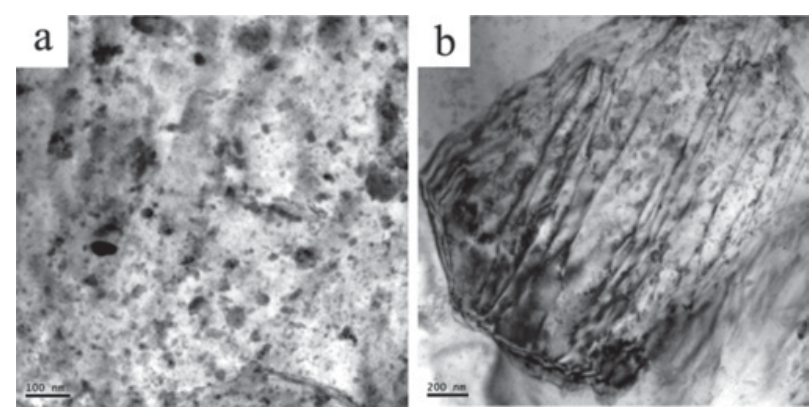

Figure 7. TEM images of oxide particles and dislocation in the extruded alloy: (a) oxide particle (b) dislocation.

\section{Conclusions}

In summary, ultrafine-grained $\mathrm{Mg}-3 \mathrm{Al}-\mathrm{Zn}$ alloy has been successfully produced. The effect of ball milling time on the microstructure and properties of the materials has been investigated. The results can be summarized as follows:

Nanocrystalline Mg-3Al-Zn alloy powders have been successively developed by different milling time. The mean grain size of the powder from TEM micrographs at $80 \mathrm{~h}$ is about $44 \mathrm{~nm}$, which is 1.58 larger than XRD result of $38 \mathrm{~nm}$.

The bulk ultrafine-grained $\mathrm{Mg}-3 \mathrm{Al}-\mathrm{Zn}$ alloy has been prepared using a combine of ball milling, vacuum hot pressing (at $633 \mathrm{~K}$ for $40 \mathrm{~min}$ ) and warm extrusion (at $473 \mathrm{~K}$ with $22 \mathrm{~mm} / \mathrm{s}$ ). The relative density at $20 \mathrm{~h}$ and grain size of the extruded alloy at $80 \mathrm{~h}$ are $98.35 \%$ and $550 \mathrm{~nm}$.

Increasing milling time, the strength of the ultrafine-fine grained alloy increases. At $60 \mathrm{~h}$, the ultimate tensile strength reaches $419 \mathrm{MPa}$. The high strength results from grain refinement strengthening, oxide dispersion strengthening and dislocation strengthening. The abnormal decrease at $80 \mathrm{~h}$ is due to excessive defects and low relative density.

\section{References}

[1] W.N. Tang, R.S. Chen, J. Zhou, E.H. Han, Mater. Sci. Eng. A 499 (2009) 404-410

[2] G. Garcés, A. Müller, E. Oñorbe, P. Pérez, P. Adeva, J. Mater. Proc. Techol. 206 (2008) 99-105

[3] Y.X. Wang, X.Q. Zeng, W.J. Ding, Scripta Mater. 54 (2006) 269-273

[4] I. Ulacia, N.V. Dudamell, F. Gálvez, Acta Mater. 58 (2010) 2988-2998 


\section{ICNFT 2015}

[5] X. Wang, L.X. Hu, K. Liu, Y.L. Zhang, J. Alloys Comp. 527 (2012) 193-196

[6] B.L. Wu, G. Wan, Y.D. Zhang, Mater. Sci. Eng. A 527 (2010) 3365-3372

[7] W. Yuan, R.S. Mishra, Sci. Eng. A. 558 (2012) 716-724

[8] A.A. Roostaei, A. Zarei-Hanzaki, H.R. Abedi, Mater. Des. 32 (2011) 2963-2968

[9] R.B. Figueiredo, T.G. Langdon, Mater. Sci. Eng. A 528 (2011) 4500-4506

[10] W.B. Fang, W. Fang, H.F. Sun, Powder Technol. 212 (2011) 161-165

[11] E. Mora, G. Garcés, E. Oñorbe, Scripta Mater. 60 (2009) 776-779

[12] E. Ayman, U. Junko, K. Katsuyoshi, Acta Mater. 59 (2011) 273-282

[13] A. Elsayed, K. Kondoh, H. Imai, Mater. Des. 31 (2010) 206-212

[14] H.F. Sun, W. Fang, W.B. Fang, J. Alloys Comp. 509 (2011) 8071-8175

[15] R.E.D. Mann, R.L. Hexemer Jr, I.W. Donaldson, Mater. Sci. Eng. A 528 (2011) 5476-5483

[16] M. Zhang, W.Z. Zhang, G.Z. Zhu, Mater Lett. 62 (2008) 4374-4376

[17] B.Y. Tang, N. Wang, W.Y. Yu, Acta Mater. 56 (2008) 3353-3357

[18] T.T. Sasaki, T. Ohkubo, K. Hono, Scripta Mater. 61 (2009) 72-75

[19] Z.Z. Shi, W.Z. Zhang, Intermetallics. 39 (2013) 34-37

[20] Q. Yang, A.K. Ghosh, Acta Mater. 54 (2006) 5159-5170 